\title{
Facets of pharmacists recommendation on over-the-counter market in Romania
}

\author{
Monica Elena Talabă, „Al. I. Cuza” University of Iasi, Romania \\ Andreia - Gabriela Andrei, „Al. I. Cuza” University of Iasi, Romania
}

\begin{abstract}
This study proposes to explore the valued aspects for persons who buy dietary supplemnets and whether pharmacists recommendation influence the buying decision and in what measure. The study is based on a initial qualitative research, followed by a quantitative research, both on pharmacists and consumers from the city of Iasi. The results differ to an extent from the findings in West European studies. Pharmacists recommendation is of subjective nature, influenced by the relation they have with the over-the-counter (OTC) producing company representative and by the trust they place in a brand or anither. From the viw of the customers, pharmacists recommendation has certain power in taking the decision to buy but it is not the most important aspect nor the only one taken into consideration. The reasearch identifies 6 important aspects for the customers when they buy OTC products and 4 aspects that the pahramacists take into account when recommending a producer od dietary supplements to the pacients.
\end{abstract}

\section{Keywords}

Dietary supplements, over-the-counter market, pharmacist recommendation, customer, focus group, Romania

\section{JEL Codes: M 37}

\section{Introduction}

As opposed to the medicine market, where the realeasing procedures of a new medicine may take up to a few years, the over-the-counter (OTC) market has fewer regulations ${ }^{1}$, which means that their releaseing is much faster - it may take only one or two months ${ }^{2}$.

This is why it is essential that providers from the health care services shouls help in the choosing process in order to make sure the OTC products are taken in safety and are effective. Even if all practioners in the health domain may help customers take decisions based on certain information, pharmacists play a key role, due to their accesibility, knowledge on alternative medicine and training in pathophisiology and pharmacology ${ }^{3}$.

As opposed to the medicine Romanian market, the OTC Romania market has not been enough researched from the view point of recommendations.

Taking this fact into consideration, we want to determine whether the paharmacist recommendation influences the Romanian pacient in buying OTC products and how

\footnotetext{
${ }^{1}$ www.wall-street.ro, 04 December 2008 (accessed on February 2010)

2 www.wall-street.ro, 06 February 2009 (accessed on February 2010)

3,5 Nickerson-Troy, J., Morse, k., White, R., Beals, A., Hudson, M. şi Kuczmarski, K. (2007), State of the Art Review: Pharmacists' Approach to Selecting Dietary/Nutritional Supplements for Patients, American Journal of Lifestyle Medicine vol. 1: pp. 490 - 498.
} 
important is this influence. Also, we explore the criteria used by pharmacists when recommending a certain deitary supplement.

\section{Literature review}

The criteria that is used by the pharmacists in recommending over-the-counter supplements is, in the first place and according to medical literature, determination of appropiateness of OTC products use for the pacients and determination of safety and effectiveness. Besides these, the pharmacists should take into consideration pacient characteristics, the most important one being level of affection, use of other drugs / OTC products and the costs ${ }^{4}$.

Also, the pharmacist respects a deonthologic code, the most standing being the The International code of Farmaceutica Deonthology.

Other results held that pharmacists recommendation take more into consideration their expertise ${ }^{5}$.

One major role of the pharmacist in pharmaceutical care is as a self-care consultant, a term introduced to describe the role of the community- based pharmacist who interfaces with consumers requesting health information, advice, or counseling ${ }^{6}$. As self-care consultants, pharmacists should be functioning as consumer advocates in health-related matters. The pharmacist is believed to be uniquely qualified to serve the public's interest in OTC product selection ${ }^{7}$. Unfortunately, some indicate that the pharmacist's role in consumer self-care consulting has not lived up to its potential ${ }^{8}$. More specifically, the domain of self-care consulting related to OTCs product recommendations and sales has often been neglected, undervalued, and/or underappreciated by many pharmacy practitioners ${ }^{9}$. A host of barriers and hindrances have been attributed to undoing the profession's vision of pharmaceutical care, many of which are not new ${ }^{10}$. Other authors believe pharmacists face two substantial hurdles, cognitive barriers stemming from needing more knowledge and skill, and situational barriers related to economic, time, and physical informational restraints when serving consumer self-care needs. Other authors found a significant number of pharmacists were not satisfied with their knowledge of appropriate OTC use for various consumer groups, such as instructing consumers on missed doses and overdoses, and counseling patients on the use of self-monitoring devices ${ }^{11}$. Pharmacists are generally not responsible for OTC inventory store purchases and store buyers rarely communicate facts concerning new products or devices to the pharmacist. This may place the pharmacist in an inconvenient position of having limited information when trying to explain a range of self-care products to meet consumer demand. Pharmacists mostly remain skeptical about recommendations of OTC products until they can be shown scientific evidence related to their safety and efficacy. A deepening situational factor influencing pharmacists' recommendations related to OTC products is economics. As third party programs provide coverage for an ever-increasing number of drugs, gross margins

\footnotetext{
${ }^{4}$ Kotecki, J., E. (2002), Factors related to pharmacists's over -the-counter recommendations, Journal of Community Health, Vol. 27, No. 4

${ }^{6}$ Srnka, QM. (1998), Pharmacists as self-care consultants, American Journal Pharm Association ,38:235.

${ }_{7}^{7}$ Covington, T. (2000), Self-care and nonprescription pharmacotherapy, American Journal Pharm Association, pp. 3-14.

${ }^{8}$ Gebhart, F. (1998). Is ORBA '90 working?, Drug Topics, 58-65.

9 Trinca, CE. (1995), The pharmacist's progress toward implementing pharmaceutical care, Amer Pharm Supp, 13:13-18

${ }^{10}$ Knapp, DA. (1979), Barriers faced by pharmacists when attempting to maximize their contribution to society, Amer J of Pharm Educ, 43:357-359.

11 Archo, R., Hillson, EM, Jankel, CA. (1994) Pharmacists' satisfaction with their pharmacy education-were they prepared for OBRA-90? APHA Ann Mt Pub,141:25.
} 
on prescriptions filled in community pharmacies have been dropping at an ever-increasing rate. Thus, to avoid losing money, pharmacists who dispense prescriptions in community pharmacies have been forced to increase their productivity and efficiency ${ }^{12}$. It has become evident that for pharmacies to survive and prosper today, they must begin to establish new sources of revenue. This is one reason that OTC product sales are so important to pharmacies. According to Barett ${ }^{13}$, a noted health care consumer fraud critic, most pharmacists who work in pharmacies face a serious potential conflict of interest in dispensing OTC products. Barrett's contention is that on one hand, pharmacists are expected to be knowledgeable about OTCs products and to dispense them in a responsible and ethical manner. On the other hand, a pharmacy's income level may be directly correlated to the sale of OTC products. Increasing sales and increasing profit margins undoubtedly are goals of every pharmacy. Furthermore, pharmacists' professional journals rarely contain articles criticizing this businesslike approach, while their trade publications carry articles urging pharmacists to compete with other retailers by using similar propaganda techniques ${ }^{14}$.

Consequentely, the aims of this study is to establish how important is the pharmacist recommendation for the customer when selling OTC products and how pharmacists differentiate among different OTC producers.

\section{Research hypothesis}

Taking into account the finding from the literature review, we frame the following hypothesis:

I1. The pharmacist play a central role in helping OTC consumer make the most appropiate decision due to their accesibility, knowledge and training in the domain and this is why his/hers recommendation influences the OTC buying decision.

I2. The customers invest pharmacists with trust and consider them an important provider for taking decisions.

I3. Due to the fact that pharmacists recommendation does not imply only ethical reasons, they discriminate among different OTC producers when they make their recommendation to the customers.

\section{Methodology}

Collecting data assumed 2 directions - customers and pharmacists. Research design meant a qualitative parte done in November 2009 - 2 focus groups with the customers and 5 in-deph inteviews with pharmacists and a quantitative part done in March 2010 - questionnaire survey, both for customers and pharmacists. The first focus group had the following characteristics: OTC customers with the age between $20-45$ years ( 7 participants), and the second: OTC customers with the age between $46-65$ years ( 7 participants). To the first focus group 71,5\% women; $28,5 \%$ men attended ( 5 women; 2 men); the second $85,7 \%$ women, $14,3 \%$ men ( 6 women; 1 men). Other criteria taken into consideration was that the decision to buy OTC products to be autonomous, not to be conditioned by the existence of a medical prescription, $50 \%$ of the respondents to have a higher income of 1000 lei, $50 \%$ of the respondents to have children. The decision made about the focus groups have been taken with a specialist - local producer of OTCs and taking into consideration literature reviw findings. Pharmacists for in-deph interview where convenience selected.

\footnotetext{
${ }^{12}$ Upjohn Company. (1995), Teaching issues for pharmaceutical management educators, Kalamazoo, MI.

${ }_{13}$ Barrett, S. (2001), Unethical behavior of pharmacists, www.quackwatch.com/01QuackeryRelated Topics/pharm.html

14 Eder, R. (1998), Caught in the middle. Drug St News, 11-14.
} 
The questionnaire survey was taken on 90 pharmacies in Iasi and 252 customers from Iasi. Customer application of the questionnaires was held in pharmacies, hazardous, with a numbering pace of 2 .

\section{Results}

The 2 focus groups done on consumers revealed the fact that the representation held by most female respondents about OTCs, resulted from spontaneous associations, was that of help, products that come to aid of body health, vegetables and fruits substitutes. For focus group participants, 'dietary supplements' inspire energy, multiple action, an easy product, with a balanced concentration of alimentary supplemnets and minerals. For those undertaking a 'supplement cure', the most frequently mentioned symptoms had been: lack of energy, somnolence, sense of weakness, weak sight, lack of appetite, sense of breakdown, nervous consumptions, weak immunitary system. Most respondent use to take OTCs mostly in two periods of the year: spring and winter, in order to prepare the body for winter or brace it in early spring. There also exists the habit to take dietary supplements before or during stressful periods, with high volumes of work or internse nerveous solicitation or after a strict diet. Students used to associate OTC consumption with exam periods and most women with children declared taking OTCs during and after giving birth. As a mean, a cure of OTCs take about 1-2 months, 2 or 3 times a year.

We give hearby the factors that influence the consumption of OTCs. The physician represents a powerfull influence factor, in most cases he/she being the one recommending respondents to take dietary supplements. In the same time, he/she takes the decision on the brand of OTC in order to be bought. The respondents settle in buying the physician recommended OTCs, placing great trust upon him/her. Many held the opinion that taking OTCs must be done after a preliminary visit and at physician recommendation, him/her knowing exactly what quantity of dietary supplements or minerals / vitamines is necessary, in what concentration and what kind of OTCs is best fit. Experience of friends, relatives has a strong role in choosing vitamines, the power of personal example having a strong persuasive effect. Pharmacist recommendation, some of the respondents declaring that it is a short-cut from going to the physician, argument for appealing directly to the counsel and advice of the pharmacist. The general impression is that, taking into consideration the interests and perceptions in certain OTCs held by the physician or pharmacist, some of the OTCs receive a faster promotion then others and fall into consumption much faster. Commercials, especially the ones on television, are high in the influence sources top, being considered a kind of televisioned 'prospect' from which information is gathered before going to the pharmacy. Presentation catalogues and other written promoting materials, existing in pharmacies, are also a source of information and influence to which many respondents appeal because, on numerous occasions, the pharmacist does not have the time or the patience to offer all the required information about vitamines.

Regarding the 5 in-deph interviwes with the pharmacists, they revealed the fact that for them, quality of a OTC is defned as a combination of number of components, dosage, reputetion of the producer and OTC effectiveness. The performance criteria taken into consideration are the correct and standardised concentration / dosage, price, reputation of the producer, quantity on stock unit (which has to check with the consumption periods), stability and resistence of the pill and the variety of presentation forms. Some pharmacists associate a high price with a better therapeutical effect of the OTC, the reason being that a high price states for high costs which derive from the high trained specialists from behind and from the high technology involved. Pharmacists admitted that, as a general rule, if a customer knows exactly what he/she wants, the discussion is reduced to the actual transaction.

The quantitative resarch tool - the questionairre - was based on the aspects that were marked as important in the qualitative part. 
Customers also had to complete the consumption frequency, in order to find out whether there is a statistic significant difference regarding the valorised aspects of the ones consumming more frequently OTCs from the ones who take OTCs only rarely butb this hypothesis was not confirmed.

Customers were asked wich of the mentioned aspects are taken into account when buying dietay supplements and what is the extent of their influence - product composition, name of producer, physician advice, pharmacist advice, form and taste, package, TV commercial and therapeutic effect on family and friends. Each item represented a 5 steps Likert scale. The items of the question consists into a scale with internal reability (alpha cronbach $=0,55)$. The most important aspect is the composition of the product. The qualitative part revealed that dosage /concentration of product is also important, but few declared that they study it when actual buying is in place, possibly because consumers do not trust themselves in evaluateing produst quality. On the second place stands the advice of the physician, followed by the therapeutic effect on family and friends and, on 4th place, the recommendation of the pharmacist.

Table 1. Results in the considered important aspects

\begin{tabular}{|l|l|}
\hline Aspects & Mean of points \\
\hline Product composition & 4.48 \\
\hline Physician advice & 4.15 \\
\hline Therapeutic effect on family, friends & 3.67 \\
\hline Pharmacist advice & 3.47 \\
\hline Producer & 3.42 \\
\hline Pill form and taste & 2.65 \\
\hline TV commercial & 2.45 \\
\hline Package & 2.12 \\
\hline (Source: Research Report) &
\end{tabular}

In order not to become a bias, the price was taken in a separate question, where respondents had to mark on a 5 steps Likert scale the importance of price when buying dietary supplements. In this context, the price obtain a mean of 3,70, that is closer to being important than neutral. In other words, price does matter but it is not a decisive aspect when buying OTCs. With regard to the previous table, the price is less important than product composition and physician advice, but more important than the effect the OTC had on family, friends and pharmacist recommendation. Lower the previous table is given, only the price has been included.

As a conclusion, pharmacist recommendation is an aspect that strongly influences the buying decision of a dietary supplement but it is not the most important; the product composition the minerals, vitamins and/or plts extracts included play the most important role, the recommendation of a physician is far more powerfull than the one of a pharmacist and so are the price and the therapeutical effect the dietary supplement had on relatves and friends. We treat with prudence the high marks the price received and put it on the current economic situation. We believe that in the situation of a normaly going economy, the elesticity of the demand of dietary supplements with regard to the price would not be so deep. 


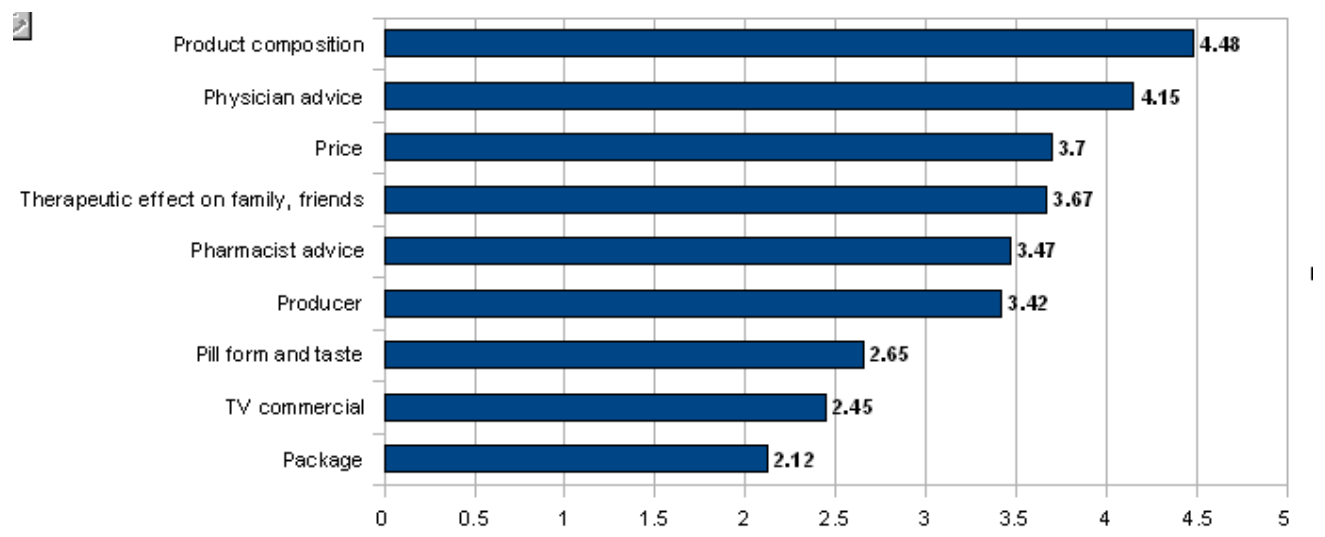

Figure 1. Results for valued aspects when buting dietary supplemnets

Afterwards we found out the opinion of the pharmacists with regard to the recommendation they make. The accent was on the reasons they recommend one brand of dietary supplement against another or one producer in front of another. The technical mean was by marking true or false on phrases that regarded these aspects for a certain producer of dietary supplements.

The aspects held into consideration were reffered to a single producer: quality of products, pharmacy discount, the price for the customer, the product variety, special promotions or offers, notoriety of brand, possesion of adequate information about the producer, technique of supplement preparation and therapeutic effect of different brands.

Most pharmacists discriminate among producers depending on the notoriety of the brand. On the 2nd place sits the criteria of the perceived quality of the products and, on the 3rd place, the price of the products. Information about the prepareing ways of the produsct, the variety of products, the promotions and special offers are not considered criteria for choosing among brands or producers. The next figure synthetize the results.

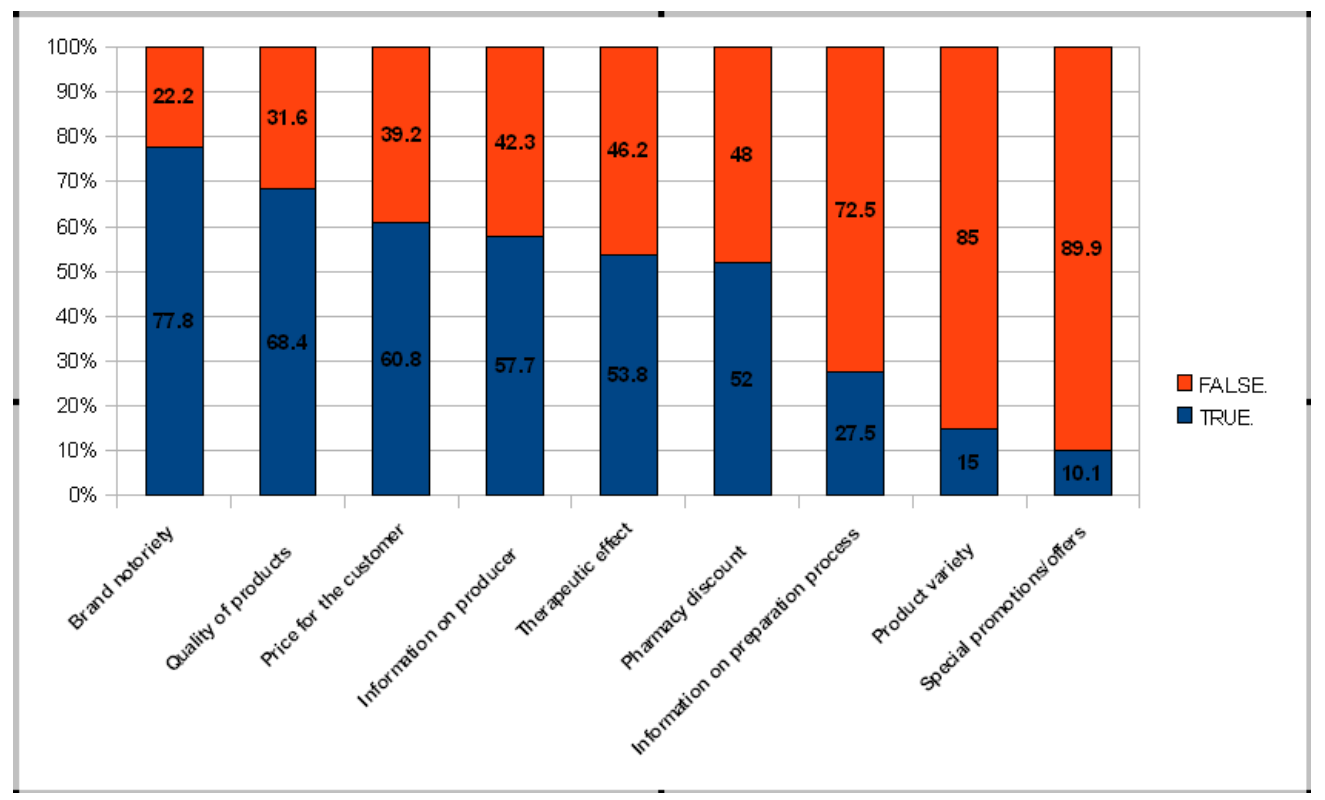

Figure 2. Aspects which stand to the base of discriminatory recommendation of pharmacists among different brands 
There are certain observations and clarifications we would like to make with regard to these results. This true or false scale is not as powerful as a Likert one. With concern to the price of the OTCs, during the qualitative research, pharmacists agreed on the point that they use to evaluate on sight the material situation of the consumers and recommend an OTC in accordance with these evaluation. In other words, the pharmacist will recommend a cheap OTC to a retired person, whereas to a well-dressed lady the pharmacists will recommend an expensive OTC.

The construct quality of products was also evaluated in dependence with 7 aspects resulted in the qualitative research: dosage, production process, ingredients, stability and resistence of pills, the producer, package, variety of products. In the first place, pharmacists understand by quality in an OTC the preparation process, which includes the respecting standards and correctdosage, as pure ingredients as kthey may be, high stable and resistent pills, high technology processes.

Pharmacists were asked to mark on a scale with constant sum how often they recommend 4 national Romania producers of dietary supplemnets. Afterwards, a single producer was selected and pharmacists were asked if they recommend him, generally; which are the reasons they recommend him from the aspects above, if they recommend him often then the others and which are the aspects from above they recommend him higher on. The majority of the pharmacists responded that they generally recommend that singular producer but only $25,6 \%$ admitted that they recommend him more often than the others. For these last ones, it is statisticaly significant that they marked in higher numbers that the relation with the reprezentative of the producer is friendlier. We conclude that pharmacists usually recommend all producers alike but when they favoure one or another, the causes reside in subjective reasons, one of them being the relation with the producer representative. This result is consistent with a well known rule in sales - ,relations sell'.

\section{Conclusions and future directions}

The hypothesis that pharmacists recommendation is important confirmed but the one that stated that pharmacists discriminate between different producers when they recommend OTCs, was not confirmed.

OTCs consumers from Iasi consider pharmacists recommendation of lesser importance that product composition, physician recommendation, therapeutic effect reported by the relatives and friends and the price of the products. Taking some nuances, the composition of the product keeps to the rational base of buying and therefore the pharmacist cannot offer a product that the consumer does not one to buy. The recommendation of the physician is law, his authority being much greater than the pharmacists. Family, friends and aquaintances represent an important point for giving recommendations, opinion and reports on effects of OTC. Besides, these represent the principal source of information for dietary supplemnets, accordingly with their answers to another question from the questionnaire. However, the price is more important than the effect reported by family and friends because one has to take into account his own budget. On the other side, the recommendation comming from the pharmacists represents an complex amalgam of evaluation of the producer and the product, of the representative of the producer they get into contact, the discount for the pharmacy and the pacient. We consider important the result that in the majority of cases $(75 \%)$ the pharmacists do not discriminate among different OTC producers but when they do there is a link between the relation the pharmacist has with the representative of the recommended producer. In order to verify this result, a replication of the study is needed, wheather on a higher sample or in a different city. A future direction is also researching the extent to which pharmacists ask pacients about their affections and medicamentation. This study is limited only to find if and how pharmacists discriminate among different producers of OTCs. 


\section{Bibliography}

1. Archo, R., Hillson, E.M., Jankel, CA. (1994) Pharmacists' satisfaction with their pharmacy education-were they prepared for OBRA-90? APHA Ann Mt Pub, 141:25

2. Barrett, S. (2001), Unethical behavior of pharmacists, www.quackwatch.com/01QuackeryRelated Topics/pharm.html

3. Covington, T. (2000), Self-care and nonprescription pharmacotherapy, American Journal Pharm Association, pp. 3-14

4. Eder, R. (1998), Caught in the middle. Drug St News, 11-14

5. Gebhart, F. (1998), Is ORBA '90 working?, Drug Topics, 58-65

6. Knapp, DA. (1979), Barriers faced by pharmacists when attempting to maximize their contribution to society, Amer J of Pharm Educ, 43:357-359

7. Kotecki, J., E. (2002), Factors related to pharmacists's over -the-counter recommendations, Journal of Community Health, Vol. 27, No. 4

8. Nickerson-Troy, J., Morse, K., White, R., Beals, A., Hudson, M. şi Kuczmarski, K. (2007), State of the Art Review: Pharmacists' Approach to Selecting Dietary/Nutritional Supplements for Patients, American Journal of Lifestyle Medicine vol. 1: pp. 490 - 498

9. Srnka, QM. (1998), Pharmacists as self-care consultants, American Journal Pharm Association ,38:235

10. Trinca, CE. (1995), The pharmacist's progress toward implementing pharmaceutical care, Amer Pharm Supp, 13:13-18

11. Upjohn Company. (1995), Teaching issues for pharmaceutical management educators, Kalamazoo, MI

12. www.wall-street.ro, 04 December 2008 (accessed on February 2010)

13. www.wall-street.ro, 06 February 2009 (accessed on February 2010) 